\title{
Japanese interpersonal competences, narcissism and moral affects
}

\author{
Masayo Uji ${ }^{1}$, Toshiaki Nagata ${ }^{2}$, Toshinori Kitamura ${ }^{3}$ \\ ${ }^{1}$ Department of Bioethics, Kumamoto University Graduate School of Life Sciences \\ ${ }^{2}$ Kyushu University of Nursing and Social Welfare \\ ${ }^{3}$ Kitamura Mental Health Institute, Tokyo
}

Email address:

ujimasayo@hotmail.co.jp (M. Uji)

\section{To cite this article:}

Masayo Uji, Toshiaki Nagata, Toshinori Kitamura. Japanese Interpersonal Competences, Narcissism and Moral Affects. Psychology and Behavioral Sciences. Vol. 2, No. 2, 2013, pp. 43-50. doi: 10.11648/j.pbs.20130202.14

\begin{abstract}
This study mainly examined two hypotheses: the first, based on Benedict's argument that Japanese culture is a "culture of shame," is that Japanese interpersonal competences are facilitated by shame but not guilt, the second, narcissism inhibits use of the Japanese interpersonal competencies. The respondents were 408 Japanese university students. NPI-S, TOSCA-3, and JICS were applied for assessing narcissism, moral affects (guilt and shame), and Japanese interpersonal competences. After confirming the JICS's two-factor structure (Perceptive Ability and Self-Restraint), structural equation modeling was used in examining the hypotheses on the relationship between narcissism, moral affects, and Japanese interpersonal competencies. The results showed that Japanese interpersonal competences were facilitated by narcissism. Proneness to shame left individuals less inclined to adopt the competences, while guilt-proneness stimulated the use of the competences. We conclude by discussing the narcissistic attitudes that are common in Japanese culture.
\end{abstract}

Keywords: Japanese Interpersonal Competences, Narcissism, Shame, Guilt

\section{Introduction}

The characteristics of interpersonal communications in Japanese culture have been described, with a focus on several aspects such as $\mathrm{Wa}$ (interpersonal harmony) [1], Amae (dependence) [2], indirect implicit non-verbal communication styles[3], the two contrastive terms Honne (actual intention) and Tatemae (ostensible reason) [1], as well as Omote (face) and Ura (mind) [4]. When compared to Western people, Japanese seem to be passive and less assertive, because they regard these attitudes as socially appropriate. One can infer from these characteristics that it is considered a virtue to be able to gauge what another is thinking or feeling, repress one's own opinions and desires in order to maintain social harmony, and focus one's attention on another's comfort. In turn, the individual expects to be treated in the same way.

The purpose of this study was to explore the relationship between Japanese interpersonal competences represented in the above mentioned attitudes, proneness to moral affects [5] and narcissism. To assess Japanese interpersonal communication competences, we adopted the Japanese Interpersonal Competence Scale (JICS). Matsudaira, Furukawa, and
Kitamura [6] concluded that JICS is a 16-item scale with a two-factor structure, the two factors being Perceptive Ability and Self-Restraint. Perceptive Ability represents the competencies involved in gauging others' feelings, needs, and expectations without explicit verbal messages. Self-Restraint represents the competencies called up on when suppressing negative feelings toward others particularly in conflictive interpersonal situations. To verify JICS factor structure, we conducted a confirmatory factor analysis (CFA) as shown in Figure 1. The goodness of fit of the model to the data will be demonstrated later in the result section. Based on this CFA, we developed a hypotheses diagram (Figure 2) to be proven by structural equation modeling (SEM). How the hypotheses were derived will be explained, using the previous scholars' theories and empirical studies.

The influence of moral affects on Japanese interpersonal competencies (W21, W22, W24, and W25 in Figure 2)

Generally speaking, people in non-Western societies are regarded as being more prone to shame [10]. This may be because in non-Western societies, collectivism is more valued than individualism. In these societies, the group's moral standards are seen as more important than those of the individual. It seems natural that people in collectivism-based 
cultures are more sensitive to external judgment than those in individualism-based cultures. If Benedict's argument that Japanese culture is a "culture of shame" is correct, the typical Japanese communication styles, "Perceptive Ability" and "Self-Restraint," can be regarded as strategies aimed at decreasing the risk of the individual feeling criticized and rejected, because these communication styles are apparently allocentric, satisfying others' expectations. Even among Japanese people, there must be the varying degrees of shame-proneness. It was presumed that the more an individual is shame-prone, the more they utilize Japanese interpersonal competences. Thus, we hypothesized that W24 and W25 in Figure 2 would be statistically significant with positive values.

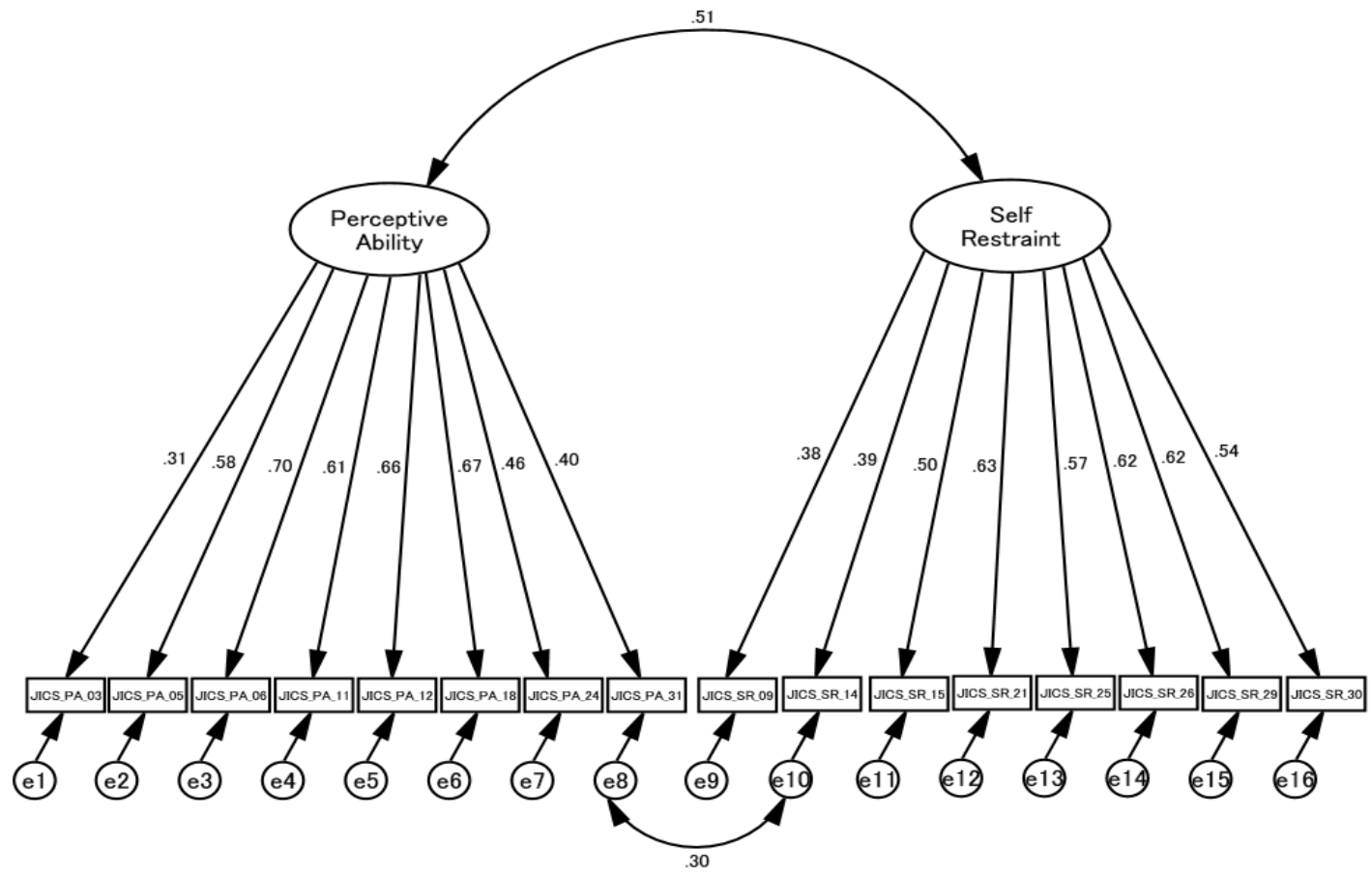

Figure 1. A confirmatory Factor Analysis of JICS.

On the other hand, as noted earlier, guilt does not affect an individual's core identity and it is characterized by criticism of their own previous actions. It was assumed that an individual with guilt-proneness does not have to utilize allocentric behaviors described in JICS for the purpose of avoiding others' criticism. Thus, we predicted that W21 and W22 in Figure 2 would not be statistically significant.

The influence of narcissism on the Japanese interpersonal competencies (W19 and W20 in Figure 2)

As noted earlier, the characteristics of typical Japanese communication styles can be summarized as suppressing their actual feelings and putting the needs of others before their own. As one of the main features of narcissism is phrased as self-centeredness, it is easy imagine that in using these communication styles, an individual's narcissism must be subdued. An individual's narcissism may inhibit their ability to utilize these communication capabilities. We hypothesized that W19 and W20 in Figure 2 would be statistically significant with negative values.

The influence of narcissism on the two moral affects (W18 and W23 in Figure2)

The narcissistic constellation, which includes grandiosity, self-centeredness, power orientation, and attitudes of entitlement, could be regarded as a defense against the fear of being rejected [11]. If narcissists cannot get external valida- tion, they experience painful shame and express narcissistic rage [12]. Inferring from these scholars' theories, narcissism appears to be a desperate struggle to avoid shame. Indeed, Gramzow and Tangney [13] showed that the shameproneness assessed by the Self- Conscious Affect and Attribution Inventory (SAAI) [14] inversely correlated with narcissism as assessed by the Narcissistic Personality Inventory (NPI) [15].

In recent years, some scholars tend to focus on the self-esteem regulating functions of narcissism [16-18], which has been discussed in the past with an emphasis on its pathological aspects $[11,12,19,20]$. From this point of view, it might be appropriate to presume that narcissism protects one from the painful and maladaptive shame that is related to low self-esteem. Thus, we presumed an inverse causal relationship between narcissism and shame-proneness: W23 in Figure 2 being statistically significant with an inverse value.

Concerning the influence of narcissism on guilt, we hypothesized that W18 would not be statistically significant, because guilt does not harm core-identity [9], and guilt-prone individuals seem to have stable self-esteems which are not easily shaken by others' evaluation.

To summarize, this study examined the following hypotheses.

1: Japanese interpersonal competences are facilitated by 
shame, but not guilt.

2: Narcissism inhibits use of the Japanese interpersonal competences.

3: Narcissism deters shame, but not guilt.

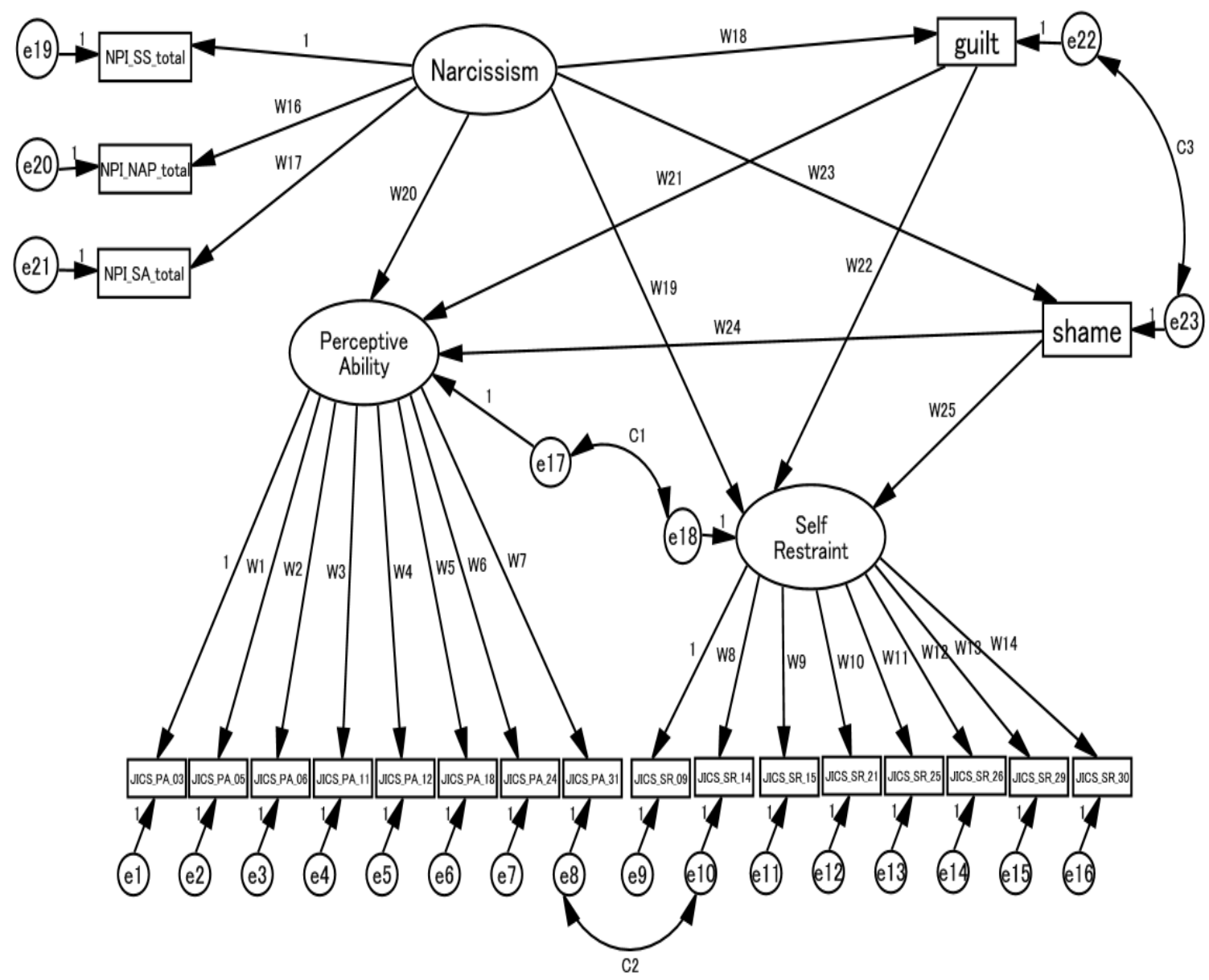

Figure 2. Path diagram: Hypothesis model for examining the relationship between Narcissism, moral affects, and Japanese Interpersonal Competences. Note: "guilt" represents Guilt-Proneness and "shame" represents Shame-Proneness as assessed by TOSCA-3.The latent variable "Narcissism" represents a factor extracted by the scores of the three subscales.

\section{Methods Procedures}

We performed a longitudinal study on depressive moods and suicidality in a population of Japanese university students, using a nine-wave four-month prospective design with students of a university in Kumamoto. The research protocol was approved by the Ethical Committee (Institutional Review Board) of Kumamoto University. Subjects were assured of anonymity and participation was voluntary. The students' majors were social welfare and nursing. The questionnaires were distributed during classes, completed by the students, then collected and sealed in envelopes. For the purpose of anonymity, aliases were used. The number of eligible students was 642 , but not all students attended class on each occasion and 3\% to $6 \%$ of the students declined participation in the study.

NPI-S was administered on the fifth occasion, TOSCA-3 on the sixth, and JICS was on the eighth. The duration between the fifth and sixth waves was three weeks, and duration between the sixth and eighth waves was five weeks.
Four hundred and eight respondents agreed to participate in all three waves. The population included 84 men and 324 women, aged $18-35$ years, with a mean age of 19.0 years (SD: 1.31).

\section{Measurements}

\subsection{Short version of Narcissistic Personality Inventory (NPI-S)}

The NPI is a self-report measure that initially contained 233 items divided into two forms. Emmons [21] revised it into a 54-item measure. In formulating a Japanese adaptation, Oshio [22] developed an 18-item measure using a 5-point Likert scale (NPI-S). We allocated between 0 and 4 points for each item. The NPI-S consists of three subcategories: Sense of Superiority (6 items), Need for Admiration and Praise (6 items), and Self-Assertion (6 items), therefore, the NPI-S total score ranges from 0 to 72 , and each subscale score ranges from 0 to 24. Sample items for Sense of Superiority are "I think I am talented," and "I have strengths that 
would be worthwhile for other people to learn from." Sample items for Need for Admiration and Praise are "I have a desire to get attention," and "I feel restless when people don't think well of me." Sample items for Self-Assertion are "I think I am type of person who can assert my own opinion," and "I act as I please without worrying about others under any circumstances." Igarashi et al. [23] conducted an exploratory factor analysis that supported a three-factor structure. The three factors corresponded to the three subscales suggested by Oshio [22].

\subsection{Japanese Interpersonal Competence Scale (JICS)}

For assessing Japanese interpersonal communication competence, we adopted the JICS. Takai and Ota [3] developed a 31-item inventory for assessing typical Japanese interpersonal communication skills, and using exploratory factor analysis, showed that the JICS uses a five-factor structure: Perceptive Ability, Self-Restraint, Social Appropriateness, Interpersonal Sensitivity, and Tolerance for Ambiguity. As explained in the introduction, Matsudaira et al. [6] concluded that JICS is a two-factor scale, composed of 16 items. These two factors were Perceptive Ability and Self-Restraint. The JICS we adopted in this study consisted of 16 items rated on a 5-point Likert scale ranging 1 (strongly disagree) to 5 (strongly agree). Eight items were included in Perceptive Ability and the other eight were included in Self-Restraint. A sample item for Perceptive Ability is "Even without a clear response from someone, I can make an educated guess of his or her intentions." A sample item for Self-Restraint is "Even if I dislike my superior (including teachers), I can treat him or her respectfully." Therefore, the total score of both Perceptive Ability and Self-Restraint range from 5 to 40 .

\subsection{Test of Self-Conscious Affect-3 (TOSCA-3)}

TOSCA-3 is a self-report measure of six self-conscious affects: Shame-Proneness, Guilt-Proneness, Externalization, Detachment, Alpha Pride, and Beta Pride. TOSCA was developed by Tangney and Dearing [24] based on Lewis's [8] definition of guilt and shame, and was revised twice to solve a few flaws, leading to the development of TOSCA-3 [25]. The TOSCA- 3 consists of a series of 11 negative and five positive scenarios with each of the six affects assessed by four or five responses. Each of the TOSCA-3 items was rated on a 5 -point scale $(1=$ not likely, $5=$ very likely $)$. A bilingual graduate student translated the TOSCA-3 into Japanese. A second bilingual graduate student translated the measure back into English and compared it with the original. In this study, of the six affect categories, the two affects that are derived from negative evaluations of the presented scenarios (Guilt-Proneness, Shame-Proneness) were used in the analysis. Each included 16 items, and thus the total score of each subscale ranged from 16 to 80 . An example of the given scenarios is "You make a big mistake on an important project at work. People were depending on you, and your boss criticized you." Respondents are then asked the degree (from not likely to very likely) to which their feelings correspond with the following sentences. The shame sentence is "You will feel like you wanted to hide" and the guilt sentence is "You would think you should have recognized the problem and done a better job."

\section{Statistics}

The path diagram shown in Figure 2 was drawn in order to examine this study's hypotheses. SEM was applied for the analysis. Guilt and shame are not mutually exclusive, and both are moral affects based on their internal attributions. With this in mind, we hypothesized a covariance between the error variables of Shame-Proneness and Guilt-Proneness (C3). Furthermore, following Matsudaira et al.'s [6] findings concerning a significant covariance between Perceptive Ability and Self Restraint, we hypothesized a covariance between the error variables of these two latent variables (C1).

All the statistical analyses were conducted using the Statistical Package for Social Science (SPSS) version 18.0 and Amos 18.0. The goodness of fit of the model to the data was expressed by the goodness of fit index (GFI), adjusted goodness of fit index (AGFI), and root mean square error of approximation (RMSEA) [26].

\section{Results}

\section{The CFA of the JICS}

The goodness of fit of the model drawn in Figure 1 to our data was as follows: $\mathrm{GFI}=.93, \mathrm{AGFI}=.90, \mathrm{RMSEA}=0.06$.

The mean scores (SD) of the subscales and the complete NPI-S, JICS, and TOSCA-3 scales are shown in Table 1.

Pearson's correlations between the NPI-S total score, the JICS subscale scores, and the TOSCA-3 subscale scores were calculated (Table 1). Significant correlations were identified between the two JICS subscales scores $(r=.44, p$ $<.001$ ), as well as between the two TOSCA-3 subscale scores $(\mathrm{r}=.61, \mathrm{p}<.001)$.

The relationship between narcissism, moral affects, and the Japanese interpersonal communication competences

Contrary to our hypothesis, two factors from the JICS, Perceptive Ability and Self-Restraint, were partially promoted by Narcissism (the standardized causal coefficients from Narcissism to Perceptive Ability and Self-Restraint were $.32, \mathrm{p}<.001$, and $.12, \mathrm{p}=.08$, respectively) (Figure 3). Furthermore, Shame-Proneness inhibited one's command of the above two Japanese interpersonal competences (the standardized causal coefficients from Shame-Proneness to Perceptive Ability and Self Restraint were, $-.17, p=.03$, and $-.18, \mathrm{p}=.02$, respectively). In contrast, Guilt-Proneness promoted good use of both of the competences (the standardized causal coefficients from Guilt-Proneness to Perceptive Ability and Self Restraint were .28, p $<.001$, and .32, $\mathrm{p}<.001$, respectively) (Figure 3).

Consistent with our hypotheses, narcissism inversely in- 
fluenced Shame-Proneness (the standardized causal coefficients from Narcissism to Shame-Proneness was -.19 , $\mathrm{p}$ $<.01$ ), but did not have a significant effect on
Guilt-Proneness (Figure 3). The goodness of fit of the model to the data was as follows: $\mathrm{GFI}=.90, \mathrm{AGFI}=.87$, $\mathrm{RMSEA}=$ 0.06 .

Table 1. Mean Scores (SD) of scales, and score correlations between the NPI-S, Perceptive Ability, Self-Restraint, and the moral affects (guilt and shame) from TOSCA-3.

\begin{tabular}{|c|c|c|c|c|c|}
\hline & NPI-S & Perceptive Ability & Self-Restraint & Guilt & Shame \\
\hline $\mathrm{N}$ & 513 & 520 & 504 & 504 & 502 \\
\hline $\begin{array}{l}\text { Mean score } \\
\text { (SD) }\end{array}$ & $\begin{array}{l}44.5 \\
(12.1)\end{array}$ & $\begin{array}{c}27.5 \\
(4.6)\end{array}$ & $\begin{array}{l}28.8 \\
(4.8)\end{array}$ & $\begin{array}{l}63.1 \\
(8.6)\end{array}$ & $\begin{array}{l}51.5 \\
(9.1)\end{array}$ \\
\hline Score range & 0-72 (4-point scale) & $8-40$ (5-point scale) & $8-40$ (5-point scale) & $16-80$ (5-point scale) & $16-80$ (5-point scale) \\
\hline \multicolumn{6}{|l|}{ NPI-S } \\
\hline Perceptive Ability & $.31 * * *$ & & & & \\
\hline Self-Restraint & .01 & $.44 * * *$ & & & \\
\hline Guilt & .04 & $.15^{* *}$ & $.14 * *$ & & \\
\hline Shame & $-.12 *$ & -.05 & .01 & $.61 * * *$ & \\
\hline
\end{tabular}

$$
* * *: p<.001, * *: p<.01, *: p<.05
$$

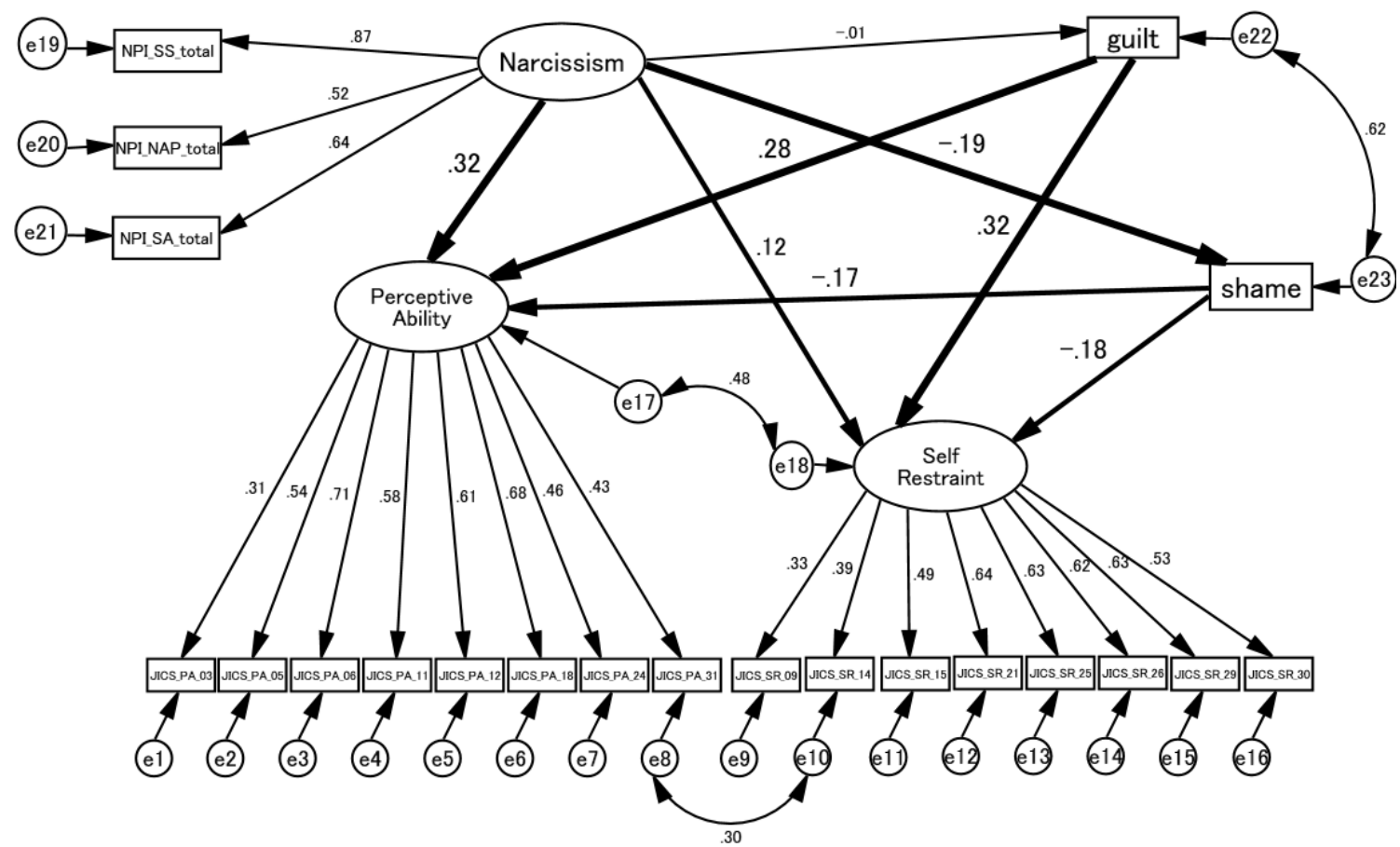

Figure 3. Causal relationships between Narcissism, Japanese Interpersonal Competences and moral affects Notes: the bold lines indicate statistically significant causalities between Narcissism, moral affects, and Japanese Interpersonal Competences, whereas the normal lines indicate statistically non-significant causalities.

\section{Discussion}

We discussed the results in the order of our hypotheses.

The direct influence of guilt on Japanese interpersonal competencies and the inverse influence of shame on Japanese interpersonal competencies

Contrary to our hypothesis, the results of this study showed that the more prone to guilt an individual was, the more likely they were to adopt Japanese interpersonal competences. On the other hand, the more prone to shame an individual was, the less likely they were to adopt Japanese interpersonal competences. As noted in the introduction, guilt is an affect wherein the individual attributes a failure to their previous actions. Guilt requires an individual to establish a flexible ego function to observe the self, feel remorse, try to compensate for their failures, and modify future actions. Inferring from these characteristics of guilt and its positive causal relationship with Japanese interpersonal competences, Japanese interpersonal competences may be regarded as having been cultivated by ego functions in order to assist the individual in adapting to the culture. On the 
contrary, an individual who is prone to shame cannot use these communication skills, indicating that Japanese interpersonal competences do not function as defenses against shame.

Some scholars dispute Benedict's idea of Japan's culture as a "culture of shame." Doi [2] attempts to clarify why "in Western eyes, Japanese sense of guilt appears to be rather sluggish." He explains that "Westerner tends to think of the sense of guilt as an inner problem....it [characteristic of the Japanese sense of guilt] shows itself most sharply when the individual suspects that his action will result in betraying the group to which he belongs." He continues, "the sense of guilt is most strongly aroused when the individual betrays the trust of the members of his own group. One could express this differently by saying that the sense of guilt is a function of human relations."

Lebra [27], in questioning Benedict's description of Japanese culture, also noted that for Japanese, "guilt is so other-oriented that feeling guilty tends to amount to feeling apologetic to a specific person." These scholars argue that for Japanese people, the strongest feelings of guilt are associated with interpersonal relationships. If this is so, this study's finding that guilt-proneness facilitates Japanese interpersonal competences suggests that these competences are mobilized for compensating for feelings of guilt.

The positive influence of narcissism on Japanese interpersonal competencies

This study showed that the Japanese interpersonal communication competences were promoted by an individual's narcissism, which was contrary to our hypothesis. As noted in the introduction, for Japanese people it is important to maintain interpersonal harmony by being less verbally expressive. An individual's narcissism contributes in establishing a culturally appropriate interpersonal relationship. We can infer from this, that in collectivism based cultures, people do not relinquish their narcissism, but it instead plays a significant role in maintaining the culture. It can be said that narcissism plays a role in directing socially appropriate behavior.

We are able to interpret this result further using the Japanese psychological characteristics, Amae. When Japanese repress self and guess others' feelings and needs, they are hoping to elicit benevolence, approval and love. In doing so, they succeed in maintaining their self-esteem, i.e. "I am valuable and approved by the significant other" and thus, fulfilling their narcissistic needs. It appears to be self-evident that behind the allocentric communication competencies, an individual's narcissism is mobilized.

It should be noted that in the case of Japanese people, the significant object does not appear to be restricted to a specific person, and may include the entire group to which they belong. Indeed, Doi [2] noted "the group for him [a Japanese person] is basically a vital spiritual prop, to be isolated from which would be, more than anything else, to lose his 'self' completely in a way that would be intolerable to him. He is obliged, therefore, to choose to belong to the group even at the cost of temporary obliteration of his self."

Narcissism's deterring effect on shame, and lack of effect on guilt

The significant inverse causal relationship between Narcissism and shame confirmed our hypothesis that narcissism functions as a defense against the awareness of painful shame. Furthermore, as predicted, narcissism did not have any effect on guilt. This result is in accordance with recent literature on the self-esteem regulating functions of narcissism [16-18].

\section{Limitations}

Several limitations of this study should be noted. The first is that the Japanese interpersonal competencies Perceptive Ability and Self-Restraint were self-evaluated, raising questions concerning accuracy. Many of the questions in this scale start with "I can" or "I am able to." Narcissistic individuals may tend to over-evaluate their abilities when answering these questions. Indeed, Ames and Kammrath [28] showed that there is a discrepancy between an individual's actual interpersonal sensitivity and their self-evaluation of their own sensitivity; in particular, narcissistic tendencies lead an individual to overestimate their competences.

Despite the fact that the JICS assesses the interpersonal competences typical to Japanese, the second limitation of this study is that the skills assessed by the JICS are only a few facets of the many elements intrinsic to Japanese communication styles. If other Japanese communication patterns, such as Amae or passive object love, had been evaluated, different results concerning their relationship with shame and guilt would have been obtained. Given these limitations, it is perhaps too early to question Benedict's concept that "Japanese culture is a culture of shame"[7].

The third limitation is that TOSCA-3 is a questionnaire based on given scenarios and it is questionable whether an individual who is evaluated as being guilt-prone by TOSCA-3 is actually prone to guilt.

\section{Application for clinical settings}

We will recommend here some ways in which the results of this study can be used in clinical situations. As discussed in previous sections, Japanese patients, in keeping with national traits, tend to be not very expressive verbally, in particular, negative feelings towards therapist. They also tend to conform to the therapist's sense of values. In both cases, their narcissism would be at work. The therapists must be careful not to interpret any negative feelings the patients may have towards them during the early stages of therapy. Such interpretation would disvalue patients' allocentric behavior, aimed at eliciting the therapists' favor, and wound patients' narcissism. Suitably modified culturally appropriate psychotherapeutic techniques are required.

The attitudes that Japanese people adopt for the purpose of following social expectations seem to be similar to those of a pathologically narcissistic individual in terms of the efforts made to maintain self through the approval of others. 
Some Japanese patients' personality organizations reveal domains that cannot be dismissed as merely cultural characteristics. In general contemporary psychodynamic views, narcissism can be classified as either healthy or pathological, although these two forms cannot always be clearly discerned $[17,29]$. Doi introduced the Japanese expressions "to have a self" and "to have no self" $[2,30,31]$. Based on the definition of "to have a self" as having self-representation, he also classified narcissism into healthy and pathological forms. Patients with narcissistic personality disorder are not able to demarcate the self from the object, and have not been able to establish a self-representation as an independent entity. For them, the object is an extension of the self, a phenomenon that Kohut referred to by using the term "self-object [32]." As Goren [11] noted, once the "coherent self" is developed, an individual does not have to "find, fix, or anchor the self in external images." They need no further external validation. Close observation of therapist-patient interaction in the clinical setting is required to discern whether narcissism is functioning at a healthy level. We have to evaluate each patient's personality in terms of establishment of core self, and self-object boundary, as well as the nature of its narcissism. The Japanese sense of value that sets group harmony above self would exacerbate the pathology of narcissistic patients, who behave over- or pseudo-adaptively toward therapists.

In conclusion, this study revealed that narcissism is at work behind the Japanese interpersonal communication competences. These competencies were facilitated by guilt but deterred by shame.

\section{Acknowledgements}

I would like to express my gratitude to the Japanese university students in Kumamoto who cooperated with us in this research. This research received no specific grant from any funding agency in the public, commercial, or not-for-profit sectors. There is no conflict of interest to declare. This research protocol was approved by the Ethical Committee of Kumamoto University (Institutional Review Board).

\section{References}

[1] K Midooka, "Characteristics of Japanese style communication," Media, Culture and Society, vol. 12, pp. 477-489, 1990.

[2] T. Doi. Anatomy of Dependence. Tokyo, Kodansha, 1971.

[3] J. Takai, H. Ota, “Assessing Japanese interpersonal communication competence," The Japanese Journal of Experimental Social Psychology, vol. 33, pp. 224-236, 1994.

[4] T. Doi, "Omote and Ura: Concepts from the Japanese 2-fold structure of Consciousness," Journal of Nervous and Mental Disease, vol. 157, pp. 258-261, 1985.

[5] D. P. Ausubel, "Relationship between shame and guilt in the socializing process," Psychological Review, vol. 62, pp. 378-390, 1955.

[6] T. Matsudaira, T. Furukawa, T. Kitamura, "Factor structure of the Japanese Interpersonal Competence Scale," Psychiatry and Clinical Neuroscience, vol. pp. 142-151, 2008.

[7] R. Benedict. The Chrysanthemum and the Sword: Patterns of Japanese Culture, Houghton Mifflin, 1946.

[8] H. B Lewis, Shame and Guilt in Neurosis. New York: Intentional University Press, 1971.

[9] J. P. Tangney, "Conceptual and methodological issues in the assessment of shame and guilt," Behaviour Research and Therapy, vol. 9, pp. 741-754, 1996.

[10] L. Anolli, P. Pascucci, "Guilt and guilt-proneness, shame and shame-proneness in Indian and Italian young adults," Personality and Individual Differences, vol. 39, pp. 763-773, 2005.

[11] E. R. Goren, Review essay: narcissism and the interpersonal self. Psychoanalytic Psychology, vol. 12, pp. 329-342, 1995.

[12] H. Kohut, "Thoughts on narcissism and narcissistic rage," International Journal of Psychoanalysis, vol. 27, pp. 360-400, 1972.

[13] R. Gramzow, J. P. Tangney, "Proneness to shame and the Narcissistic Personality," Personality and Social Psychology Bulletin, vol. 18, pp. 369-376, 1992.

[14] J. P. Tangney, S. Burggraf, H. Hamme, B. Domingos. Assessing individual differences in proneness to shame and guilt. The Self-Conscious Affect and Attribution Inventory. Presented at a poster session at the meeting of the Eastern Psychological Association, Buffalo, NY, 1988.

[15] R. Raskin, C. S. Hall, "A narcissistic personality inventory," Psychological Reports,“vol. 45, pp. 590-590, 1979.

[16] W. K. Campbell, J. D. Foster, A. B. Brunell. "Running from shame or reveling in pride? Narcissism and the regulation of self-conscious emotions. COMMENTARIES on "Putting the Self into Self-Conscious Emotions: A Theoretical Model"' Psychological Inquiry, vol. 15, pp. 150-153, 2004.

[17] R. Stolorow, "Toward a functional definition of narcissism," International Journal of Psychoanalysis, vol. 56, pp. 179-185, 1975.

[18] J. L. Tracy, R. W. Robins, "Putting the self into self-conscious emotions: a theoretical model," Psychological Inquiry, vol. 15 (2), pp. 103-125, 2004.

[19] H. Kohut, "Forms and transformations of narcissism," Journal of the Psychoanalytic Association, vol. 14, pp. 243-272, 1966.

[20] T. Millon, Narcissistic personality disorders: the egotistic pattern. In Millon, T. (Ed.), Disorders of personality DSM-IV $^{\mathrm{TM}}$ and beyond. New York, John Wiley \& Son, Inc, 1996, pg393-427.

[21] R. A. Emmons, "Factor analysis and construct validity of the Narcissistic Personality Inventory," Journal of Personality Assessment, vol. 48, pp. 291-300, 1984.

[22] S. Oshio, Jikoai no seinen shinrigaku [Adolescence psychology of narcissism]. Kyoto: Nakanishiya, 2004. 
[23] H. Igarashi, C. Hasui, C., M. Uji, M. Shono, T. Nagata, Z. Chen, T. Kitamura, Narcissistic and Borderline Personality Traits: their relationship with childhood abuse experiences in a student population in Japan. In Villanueva, J. O. (Ed.), Personality traits: classification, effects and changes. New York: Nova Publishers, 2010,pg. 65-82.

[24] J. P. Tangney, R. L. Dearing, Assessing shame and guilt, In Salevey, P. (Ed.), Shame and guilt. New York, London, Guilford Press, 2002, pg. 27.

[25] J. P. Tangney, R. Dearing, P. Wagner, R. Gramzow, The Test of Self - Conscious Affect -3 (TOSCA-3). Fairfax, VA: George Mason University, 2000.

[26] J. L. Arbuckle, W. Wothke, Amos 4.0 User's Guide. Small Waters Cooperation, 1995.

[27] T. S. Lebra, "Shame and guilt: a psychocultural view of the Japanese self," Ethos, vol. 11, pp. 192-209, 1983.
[28] D. R. Ames, L. K. Kammrath, "Mind-reading and metacognition: narcissism, not actual competence, predicts self-estimated ability," Journal of Nonverbal Behavior, vol. 28, pp. 187-209, 2004.

[29] S. E. Pulver, "Narcissism: The term and the concept. Journal of American Psychoanalytic Association," vol. 18, pp. 319-341, 1970.

[30] T. Doi, "narcissism no riron to jiko no hyosho [The theory of narcissism and the psychic representation of self]" Seisin bunseki kenkyu [Japanese Journal of Psychoanalysis], vol. 7, pp. 7-9, 1959a.

[31] T. Doi, "Jibun to Amae no Seisinbyori [Psychopathology of Jibun and Amae]. Seishin shinkei gaku zassi [Psychiatria et Neurologia Japonica], " vol. 61, pp. 149-162, 1959 b.

[32] H. Kohut, The analysis of the self. International University Press, Madison, 1971. 